OPEN ACCESS

Edited by:

Jörn Rittweger,

Deutsches Zentrum für Luft- und

Raumfahrt (DLR), Germany

Reviewed by:

Brian Crucian,

Johnson Space Center, United States

Oliver Ullirich

Universität Zürich, Switzerland

*Correspondence:

Jean-Pol Frippiat

jean-pol.frippiat@univ-lorraine.fr

tThese authors have contributed equally to this work.

Specialty section:

This article was submitted to Environmental, Aviation and Space

Physiology,

a section of the journal

Frontiers in Physiology

Received: 02 March 2018

Accepted: 20 April 2018

Published: 09 May 2018

Citation:

Gaignier F, Legrand-Frossi C,

Stragier E, Mathiot J, Merlin J-L,

Cohen-Salmon C, Lanfumey $L$ and

Frippiat J-P (2018) A Model

of Chronic Exposure to Unpredictable Mild Socio-Environmental Stressors

Replicates Some Spaceflight-Induced

Immunological Changes.

Front. Physiol. 9:514.

doi: 10.3389/fphys.2018.00514

\section{A Model of Chronic Exposure to Unpredictable Mild Socio-Environmental Stressors Replicates Some Spaceflight-Induced Immunological Changes}

\author{
Fanny Gaignier ${ }^{1 \dagger}$, Christine Legrand-Frossi ${ }^{1 \dagger}$, Emilien Stragier ${ }^{2}$, Julianne Mathiot ${ }^{1}$, \\ Jean-Louis Merlin ${ }^{3}$, Charles Cohen-Salmon ${ }^{4}$, Laurence Lanfumey ${ }^{2}$ and \\ Jean-Pol Frippiat ${ }^{1 *}$
}

1 Stress Immunity Pathogens Laboratory, EA7300, Faculty of Medicine, Université de Lorraine, Vandoeuvre-lès-Nancy, France, ${ }^{2}$ INSERM UMR894, Centre de Psychiatrie et Neuroscience, Paris, France, ${ }^{3}$ Institut de Cancérologie de Lorraine, Service de Biopathologie and CNRS UMR 7039 CRAN, Université de Lorraine, Vandœuvre-lès-Nancy, France, ${ }^{4}$ INSERM U1141, PROTECT, Université Paris Diderot, Sorbonne Paris Cité, Hôpital Robert Debré, Paris, France

During spaceflight, astronauts face radiations, mechanical, and socio-environmental stressors. To determine the impact of chronic socio-environmental stressors on immunity, we exposed adult male mice to chronic unpredictable mild psychosocial and environmental stressors (CUMS model) for 3 weeks. This duration was chosen to simulate a long flight at the human scale. Our data show that this combination of stressors induces an increase of serum $\mathrm{IgA}$, a reduction of normalized splenic mass and tends to reduce the production of pro-inflammatory cytokines, as previously reported during or after space missions. However, CUMS did not modify major splenic lymphocyte sub-populations and the proliferative responses of splenocytes suggesting that these changes could be due to other factors such as gravity changes. Thus, CUMS, which is an easy to implement model, could contribute to deepen our understanding of some spaceflight-associated immune alterations and could be useful to test countermeasures.

Keywords: mouse model, spaceflight, stress, lymphocytes, antibodies, cytokines

\section{INTRODUCTION}

Human bio-astronautic programs have substantially expanded over the last 50 years. Space is an adverse environment in which human encounter different types of stressors that can be classified in three categories: radiations, mechanical (microgravity and hypergravity), and socio-environmental (e.g., confinement, isolation, disrupted circadian rhythm. ..) stressors. Medical and physiological findings from these missions have demonstrated that this extreme environment negatively impacts almost all physiological systems. It causes muscle atrophy, bone demineralization, cardiovascular and metabolic dysfunctions, impaired cognitive processes and reduces immunological competence. Regarding this last point, it was shown that 15 of the 29 astronauts involved in Apollo missions

Abbreviations: CUMS, chronic unpredictable mild psychosocial and environmental stressors. 
developed bacterial or viral infections during, immediately after, or within 1 week of landing (Kimzey, 1977). In addition, the first study based on medical data collected on 46 astronauts who spent 6 months onboard the International Space Station, showed that $46 \%$ of them had to face immunological problems (Crucian et al., 2016a). These observations demonstrate that, on average, spaceflight affects the immune system of $50 \%$ of the astronauts and that immune dysregulations occurs during spaceflight, confirming in-flight dysregulation distinct from the influences of landing and readaptation following deconditioning (Crucian et al., 2015, 2016a,b).

There have been several studies to understand how spaceflight environment impairs innate immunity and $\mathrm{T}$ cell responses (reviewed in Guéguinou et al., 2009; Frippiat et al., 2016). It has been shown that the phagocytic and oxidative functions of neutrophils are affected by spaceflight conditions (Kaur et al., 2004; Rykova et al., 2008) and that astronauts' monocytes exhibit phenotypic and cytokine-production deregulations, a reduced ability to engulf $E$. coli, elicit an oxidative burst and degranulate (Kaur et al., 2005, 2008; Rykova et al., 2008; Crucian et al., 2011). Low natural killer cell cytotoxicity and a delay in responses to hypersensitivity skin tests were observed (Taylor and Janney, 1992; Meshkov and Rykova, 1995). Reactivation of latent herpes viruses has frequently been reported and can be considered as a good biomarker of spaceflight-induced weakening of cell-mediated immunity (Mehta et al., 2000; Pierson et al., 2005; Cohrs et al., 2008). Numerous studies did also investigate reduced $\mathrm{T}$ cell activation under low gravity conditions (Cogoli et al., 1984; Cogoli, 1993a,b; Gridley et al., 2009) and highlighted that almost all cellular parameters can be affected such as : (i) genetic expression, as shown by lower expressions of Interleukin-2 (IL-2) and IL-2 receptor alpha chain (Walther et al., 1998); (ii) cell-cell interactions and cytoskeleton structure, as T lymphocytes were found to be highly motile under microgravity while the motility of monocytes was severely reduced and the structure of their cytoskeleton was modified (Sciola et al., 1999; Cogoli-Greuter, 2004; Meloni et al., 2004, 2006, 2011); (iii) signal transduction, as PKA and NF- $\mathrm{BB}$ signaling pathways were shown to contribute to $\mathrm{T}$ cell dysfunction under altered gravity (Boonyaratanakornkit et al., 2005; Chang et al., 2012; Martinez et al., 2015) and (iv) disturbed expression of cell cycle regulatory proteins (Thiel et al., 2012).

Humoral immunity has been less extensively studied, and inconsistent data were reported after long-term flights. Konstantinova et al. (1993) reported increased levels of serum IgA and IgG, while Rykova et al. (2008) indicated that the total amounts of serum IgA, IgG, and IgM were unchanged. Using the amphibian Pleurodeles waltl as an animal model (Frippiat, 2013), we previously showed that spaceflight affects antibody production in response to an antigenic stimulation (Boxio et al., 2005; Bascove et al., 2009). We also demonstrated that somatic hypermutations, that diversify antibody-binding sites to improve their affinity, occur following immunization in space but at a frequency two-times lower than on Earth (Bascove et al., 2011). Another space experiment, coupled with several ground-based simulations of stressors encountered during a mission onboard the ISS, demonstrated that the transcription of IgM heavy chains and of an early B cell transcription factor are modified only when embryos of $P$. walt are subjected to gravitational changes, suggesting a change in B lymphopoiesis (Huin-Schohn et al., 2013).

Given the limitations in the availability and the experimental protocols that can be carried out with samples from astronauts as well as the cost and the limited number of space experiments, various ground-based models have been developed to reproduce the effects of spaceflight conditions on an organism. The most widely used to reduce gravity constraint are head-down tilt bed rest for humans (Hargens and Vico, 2016) and anti-orthostatic tail suspension for rodents (Globus and Morey-Holton, 2016), while continuous centrifugation of animals are used to increase gravitational force. Recently, we showed that hypergravity and simulated microgravity (anti-orthostatic suspension) impair the proliferative responses of murine lymphocytes (Guéguinou et al., 2012; Gaignier et al., 2014). Moreover, we showed that anti-orthostatic suspension induces a decrease of murine B lymphopoiesis, demonstrating that our hypothesis deduced from studies performed with $P$. walt lembryos that developed onboard the ISS was correct (Lescale et al., 2015). In the same way, gravitational changes were shown to affect $\mathrm{T}$ cell development and the repertoire of $\mathrm{T}$ cell receptors, suggesting that host immunity could be modified (Woods et al., 2003, 2005; Ghislin et al., 2015).

However, gravitational changes are not the only stressors encountered during space missions. Socio-environmental factors (e.g., confinement, isolation, circadian rhythm misalignment...) have to be considered because they can affect immune parameters (Choukèr, 2012; Frippiat et al., 2016). Here, to simulate socioenvironmental stresses encountered during a space mission, we exposed adult male mice, as up to now most astronauts were males, to chronic unpredictable psychosocial and environmental stressors of various nature and mild intensity separated by resting periods (CUMS model). We chose this model, involving only mild stressors, because astronauts are heavily trained before flying and are enthusiastic to go to space. This positive rewarding effect, understandable after such long training, might compensate at least partially the negative effects of missionassociated stressors while for mice there is no rewarding effects. The second reason is that this model does not involve food and water deprivation, which is not something endured by astronauts either. The third reason is that CUMS involves resting periods to reflect the fact that ISS crew activities involve periods of notable stress (e.g., dockings, extra-vehicular activities) separated by less stressing periods. We therefore believed that this model comes reasonably close to the diversity and intensity of socio-environmental stressors encountered by astronauts while they are aboard the ISS (Table 1). Furthermore, it is easier to implement and more accessible than undersea deployment, Antarctic winter-over missions or Mars simulation.

Our data show that 3 weeks of CUMS exposure induces an increase of serum IgA, a reduction of normalized splenic mass and tends to decrease pro-inflammatory cytokine production, as previously reported during or after space missions. CUMS could therefore contribute to (i) deepen our understanding of some 
TABLE 1 | Comparison of socio-environmental stressors encountered during space missions with those delivered using the CUMS model, and limitations of this model.

\begin{tabular}{|c|c|c|}
\hline $\begin{array}{l}\text { Socio-Environmental stressors } \\
\text { encountered during spaceflights }\end{array}$ & $\begin{array}{l}\text { Socio-Environmental stressors applied in } \\
\text { the CUMS model }\end{array}$ & Limitations of this model \\
\hline Confinement throughout the mission. & Mice confined in a small cage during 1 or $2 \mathrm{~h}$. & $\begin{array}{l}\text { From an ethical point of view, mice cannot be confined } \\
\text { during extended periods while astronauts are confined } \\
\text { for several months in the ISS. }\end{array}$ \\
\hline Isolation from friends and family. & $\begin{array}{l}\text { Mice, which are sociable animals, were isolated } \\
\text { during the whole CUMS procedure. }\end{array}$ & \\
\hline Disrupted circadian rhythm. & $\begin{array}{l}15 \text { h overnight period with permanent light }+ \\
\text { reversed light/dark cycle between Friday } \\
\text { evening and Monday morning. }\end{array}$ & $\begin{array}{l}\text { Astronauts observe } 16 \text { sunrises and sunsets during a } \\
24 \mathrm{~h} \text { period. }\end{array}$ \\
\hline Crew tension and other interpersonal issues. & Pair housing during $2 \mathrm{~h}$. & Pair housing is of a limited duration. \\
\hline Perturbation of spatial references. & $30^{\circ}$ cage tilt for 1,2 , or $15 \mathrm{~h}$. & Cage tilt is of a limited duration. \\
\hline $\begin{array}{l}\text { Lower dietary intake, despite enough available } \\
\text { food, perhaps due to changes in eating habits } \\
\text { and rituals. }\end{array}$ & $\begin{array}{l}15 \text { h overnight period with difficult access to } \\
\text { food, without a reduction in the daily food } \\
\text { ration. }\end{array}$ & \\
\hline Uncomfortable living conditions. & $\begin{array}{l}15 \text { h overnight period in a soiled cage (mice do } \\
\text { not like wet litter). }\end{array}$ & \\
\hline
\end{tabular}

spaceflight-associated immune alterations and (ii) be useful to test countermeasures.

\section{MATERIALS AND METHODS}

\section{Animals}

Experiments were conducted on 8-week-old C57Bl/6NCrl male mice with $20 \mathrm{~g}$ mean body weight purchased from Charles River Laboratories (Bois des Oncins, France). On arrival, animals were housed for 5 days in groups of five in standard cages in the animal facility of the INSERM UMR894 laboratory (Paris). Animals were provided food and water ad libitum in a quiet room with constant temperature $\left(22^{\circ} \mathrm{C}\right), 50 \%$ relative humidity and $12 \mathrm{~h}$ light/dark cycles (dark period $8 \mathrm{pm}-8 \mathrm{am}$ ). Then, animals were randomly divided in two groups: one control group and one group subjected to CUMS for 21 days. CUMS and control mice were housed in different rooms. Experiments were repeated twice. This study was carried out in accordance with the National Legislation and the Council Directive of the European Communities on the Protection of Animals Used for Experimental and Other Scientific Purposes (2010/63/UE). Moreover, the CUMS protocol was approved by the French Ministry of Research (authorization 00966.02).

\section{Chronic Exposure to Psychosocial and Environmental Stressors (CUMS)}

Mice were isolated (one mice per cage) and subjected to six mild environmental or psychosocial stressors (Table 1): $30^{\circ}$ cage tilt for $1 \mathrm{~h}, 2 \mathrm{~h}$, or $15 \mathrm{~h}$; confinement in a small cage $(11 \mathrm{~cm} \times 8 \mathrm{~cm} \times 8 \mathrm{~cm})$ for $1 \mathrm{~h}$ or $2 \mathrm{~h}$; paired housing for $2 \mathrm{~h}$; one $15 \mathrm{~h}$ overnight period with difficult access to food (without a reduction in the daily food ration); one $15 \mathrm{~h}$ overnight period with permanent light and one $15 \mathrm{~h}$ overnight period in a soiled cage ( $50 \mathrm{ml}$ of water in $1,000 \mathrm{ml}$ of bedding). These stressors were delivered according to Pardon et al. (2000). Stress periods that lasted $1 \mathrm{~h}$ in the morning, $2 \mathrm{~h}$ in the afternoon, and
$15 \mathrm{~h}$ at night ( $6 \mathrm{pm}-9 \mathrm{am})$ were always separated by stress-free intervals of at least $2 \mathrm{~h}$ to avoid any habituation process. Animals were also placed on a reversed light/dark cycle between Friday evening and Monday morning. This procedure was scheduled over a 1-week period and repeated throughout the 3 weeks of experimentation. The control group was left undisturbed in another room of the animal facility, five mice per standard cage $(37.5 \mathrm{~cm} \times 21.5 \mathrm{~cm} \times 18 \mathrm{~cm})$.

\section{Sample Collection}

After 21 days of CUMS exposure, mice were weighed and put to death. Animals were killed between 8 and 10 am to avoid fluctuations of corticosterone concentration due to circadian rhythm. Trunk blood was collected, allowed to clot at ambient temperature for $15 \mathrm{~min}$ and centrifuged at $4^{\circ} \mathrm{C}$ and $4,000 \mathrm{rpm}$ for $15 \mathrm{~min}$ to obtain serum samples that were stored at $-80^{\circ} \mathrm{C}$ until analysis. The spleen and the thymus were also collected. The spleen was placed into sterile tubes containing $3 \mathrm{ml}$ of RPMI 1640 medium (PAA, Pashing, Austria) to perform lymphocyte studies.

\section{Immunoglobulin Assays}

The concentrations of serum immunoglobulins (IgA, IgG, and IgM) were determined using Mouse ELISA quantitation sets according to manufacturer instructions (Bethyl Laboratories Inc., Montgomery, TX, United States). Concentrations were calculated using a 4-parameter curve and expressed in $\mu \mathrm{g} / \mathrm{ml}$.

\section{Corticosterone Quantification}

Corticosterone levels in serum samples were measured without any extraction procedure using the Corticosterone Enzyme Immunoassay kit (Arbor Assays, Ann Arbor, MI, United States). Concentrations were calculated using a 4-parameter curve and expressed in $\mathrm{ng} / \mathrm{ml}$.

\section{Lymphocyte Populations in the Spleen}

Spleens were dissociated in RPMI 1640 medium. Red blood cells were lysed with $\mathrm{NH}_{4} \mathrm{Cl} 140$ mM (eBioscience, San Diego, 
CA, United States) before counting nucleated cells with a hemocytometer. To evaluate lymphocyte sub-populations, $10^{6}$ splenocytes were incubated for $15 \mathrm{~min}$ at $4^{\circ} \mathrm{C}$ in the dark with a mixture of four anti-mouse monoclonal antibodies: ECD anti-CD19 (clone 6D5, Beckman Coulter, Marseille, France), $\mathrm{APC}$ anti-CD3 $\varepsilon$ (clone 17A2, eBioscience), PE anti-CD4 (clone RM4-5, eBioscience) and PE-Cy7 anti-CD8 $\alpha$ (clone 53-6.7, eBioscience). Immunophenotyping was carried out using a five-color FC500 flow cytometer (Beckman Coulter). Data were analyzed using the FlowJo v7.6.5 software (Tree Star Inc., Ashland, OR, United States).

\section{In Vitro Stimulations}

Two mitogens, lipopolysaccharide (LPS) from Escherichia coli (Sigma-Aldrich) and concanavalin A (ConA) from Canavalia ensiformis (Sigma-Aldrich, St Louis, MO, United States), were used to stimulate splenocytes. Splenocytes were adjusted to $10^{7}$ cells/ml in RPMI 1640 culture medium supplemented with 10\% heated FCS, $100 \mathrm{U}$ penicillin, $100 \mu \mathrm{g} / \mathrm{ml}$ streptomycin and $2 \mathrm{mM}$ glutamine (Sigma-Aldrich). Cells were then dispensed in $50 \mu \mathrm{l}$ quadruplicates into a 96-well tissue culture plate containing $50 \mu \mathrm{l}$ of culture medium without (unstimulated cells) or with (stimulated cells) mitogen at a final concentration of $5 \mu \mathrm{g} / \mathrm{ml}$. This plate was incubated for $48 \mathrm{~h}$ at $37^{\circ} \mathrm{C}$ and $5 \% \mathrm{CO}_{2}$. Then, $20 \mu \mathrm{l}$ of MTS (Promega, Madison, WI, United States) was added into three wells to determine the number of viable cells. After $4 \mathrm{~h}$ of incubation at $37^{\circ} \mathrm{C}$ and $5 \% \mathrm{CO}_{2}$, the optical density (OD) was measured at $490 \mathrm{~nm}$ and an index of proliferation (IP) was calculated using the following formula: IP $=$ OD $(490 \mathrm{~nm})$ of stimulated cells/OD (490 nm) of unstimulated cells. The supernatant from the last well was frozen at $-80^{\circ} \mathrm{C}$ for cytokine quantification.

\section{Quantification of Cytokines}

Mouse sera and culture supernatants were thawed just before analysis. Cytokines (IFN $\gamma$, IL-12p70, IL-4, IL-5, IL-6 and TNF $\alpha$ ) were quantified using the Bio-Plex ${ }^{\circledR}$ Instrument (Bio-Rad, Ivry sur Seine, France) and the ProcartaPlex Mouse Essential Th1/Th2 Cytokine Panel (Affymetrix, Santa Clara, CA, United States). Concentrations were determined using the Bio-Plex ${ }^{\circledR}$ software and expressed in $\mathrm{pg} / \mathrm{ml}$. The sensitivity of this $\mathrm{kit}$ is $0.09 \mathrm{pg} / \mathrm{ml}$ for IFN $\gamma, 0.21 \mathrm{pg} / \mathrm{ml}$ for IL-12p70, $0.03 \mathrm{pg} / \mathrm{ml}$ for IL-4, $0.32 \mathrm{pg} / \mathrm{ml}$ for IL-5, $0.21 \mathrm{pg} / \mathrm{ml}$ for IL-6 and $0.39 \mathrm{pg} / \mathrm{ml}$ for TNF $\alpha$.

TABLE 2 | Body weights, lymphoid organ normalized weights and serum corticosterone concentration in control and CUMS mice.

\begin{tabular}{lllll}
\hline & $\begin{array}{l}\text { Body } \\
\text { weight (g) }\end{array}$ & $\begin{array}{l}\text { Normalized } \\
\text { thymus } \\
\text { weight } \mathbf{( m g / g )}\end{array}$ & $\begin{array}{l}\text { Normalized } \\
\text { spleen weight } \\
\mathbf{( m g / g )}\end{array}$ & $\begin{array}{l}\text { Corticosterone } \\
\text { (ng/ml) }\end{array}$ \\
\hline Control & $25.38 \pm 0.4$ & $2.16 \pm 0.09$ & $2.97 \pm 0.08$ & $35.56 \pm 6.5$ \\
CUMS & $25.15 \pm 0.4$ & $2.08 \pm 0.10$ & $2.59^{*} \pm 0.06$ & $35.64 \pm 7.5$ \\
\hline
\end{tabular}

Normalized thymus and spleen weights were calculated using the formula: organ weight/body weight. Serum corticosterone concentrations were determined by ELISA. ${ }^{*} p=0.0174$ versus control as determined using an unpaired t-test. $n=10$. Results representative of two CUMS exposures. Data are presented as mean values \pm SEM.

\section{Statistics}

SPSS v13.0 software (SPSS Inc., Chicago, IL, United States) was used to perform statistical analyses. Outlier values were determined by creating a boxplot for each studied group. Once normality and homogeneity of variances were assessed, as determined by Kolmogorov-Smirnov and Levene tests, an unpaired $t$-test was performed. When data were not normally distributed, a Mann-Whitney non-parametric test was performed. $p$-values $<0.05$ indicate significance. $p$-values comprised between 0.05 and 0.10 indicate trend. All data are presented as means \pm standard error of the means (SEM).

\section{RESULTS}

\section{Evaluation of Stress After 21 Days of CUMS Exposure}

To assess the stress status of mice after 21 days of CUMS exposure, we first determined thymus and spleen weights and

TABLE 3 | Lymphocyte sub-populations in the spleens of control and CUMS mice.

\begin{tabular}{|c|c|c|}
\hline & Control & CUMS \\
\hline Number of nucleated cells & $97.5 \pm 12.1$ & $99.5 \pm 7.4$ \\
\hline$\%$ of total lymphocytes & $69.6 \pm 3.6$ & $68.5 \pm 2.9$ \\
\hline$\%$ of CD19+ cells & $39.5 \pm 2.5$ & $44.6 \pm 1.5$ \\
\hline$\%$ of $\mathrm{CD}^{+}$cells & $52.0 \pm 3.0$ & $51.1 \pm 1.5$ \\
\hline$\%$ of $\mathrm{CD}^{+} \mathrm{CD}^{+}$cells & $18.6 \pm 1.3$ & $19.6 \pm 0.8$ \\
\hline$\%$ of $\mathrm{CD}^{+}{ }^{+} \mathrm{CD} 4^{+}$cells & $31.0 \pm 1.8$ & $28.9 \pm 0.8$ \\
\hline
\end{tabular}

Splenic nucleated cells were counted in CMUS $(n=6)$ and control $(n=8)$ mice after red blood cell lysis with $\mathrm{NH}_{4} \mathrm{Cl}$ and analyzed by flow cytometry. Results representative of two CUMS exposures. Data are shown as means \pm SEM. No significant difference was found using an unpaired t-test.

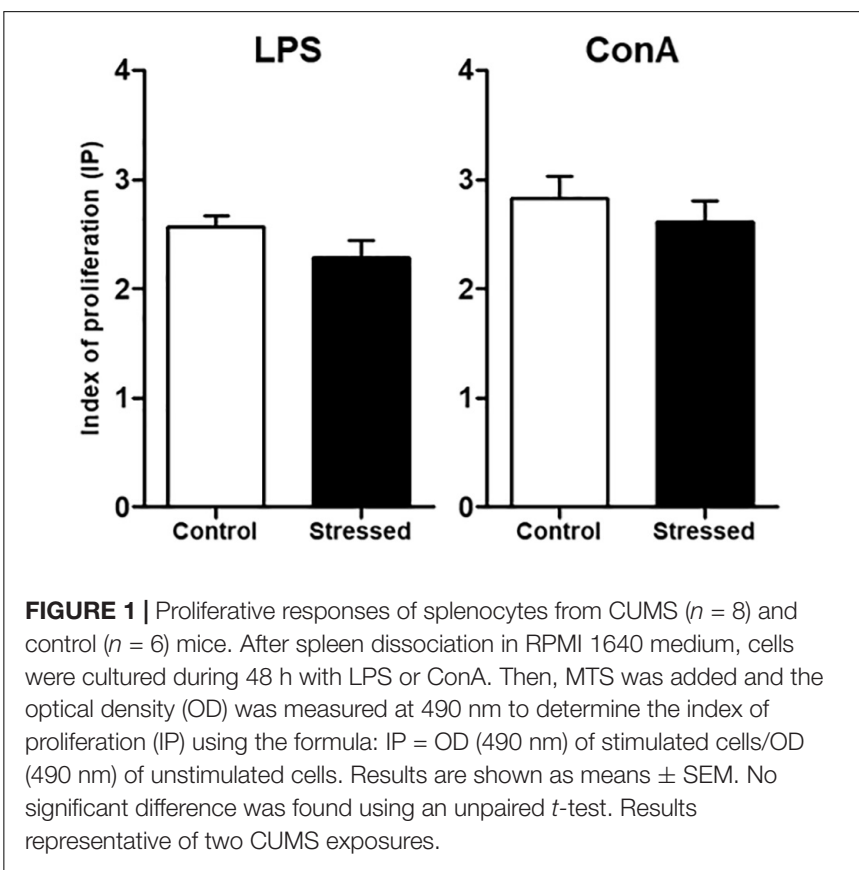


normalized these values to body weights (Table 2). No significant difference appeared between normalized thymus weights for the two groups of mice. However, a statistically significant reduction in normalized spleen weight was observed for CUMS mice ( $p=0.0174)$. Finally, we quantified corticosterone, the most studied stress hormone in rodents. Our results show that its concentration was the same in the serum of mice exposed to 21 days of CUMS and control mice (Table 2).

\section{Splenic Lymphocyte Populations}

To understand why splenic mass is decreased in CUMS mice, we determined the number of nucleated cells in that organ. Table 3 shows that this number was the same in both groups of mice. Furthermore, no statistically significant difference was observed between total lymphocyte percentages (Table 3 ).

To precise these data, we determined the percentages of major splenic lymphocyte sub-populations by immunophenotyping. CD19 was used to identify B cells, CD3 to identify T cells, $\mathrm{CD} 3+\mathrm{CD} 8$ to identify cytotoxic $\mathrm{T}$ cells and CD3 + CD4 to identify helper $\mathrm{T}$ cells. Cells positive for each phenotypic marker, or a combination thereof, were quantified within the viable lymphocyte gate. Our data show that the percentages of

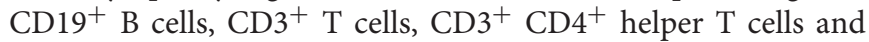
$\mathrm{CD}^{+}{ }^{+} \mathrm{CD}^{+}$cytotoxic $\mathrm{T}$ cells did not vary between the two experimental groups (Table 3 ). These results indicate that 3 weeks of CUMS exposure does not seem to modify major lymphocyte sub-populations in the spleen.

\section{Splenocyte Proliferative Response}

We then questioned whether splenic immune cells proliferative responses could be affected by 21 days of CUMS exposure. To address this question, splenocytes were stimulated with LPS or ConA during $48 \mathrm{~h}$. This was the minimal duration to observe a proliferative response according to our previous study (Guéguinou et al., 2012). Our results show that the LPS- and ConA-induced proliferative responses were not different between the two groups of mice (Figure 1). Thus, these responses were not affected after 3 weeks of CUMS exposure. We also quantified a panel of six Th1/Th2 cytokines into the culture medium following these stimulations (Figure 2). Our results revealed trends toward a reduction of pro-inflammatory cytokines production by CUMS splenocytes following both stimulations. Interestingly, IL-12p70 concentration also tended to be lower in the sera of CUMS mice ( $p=0.0634$ ) (Figure 3 ). Taken together, these data suggest that CUMS exposure could reduce the production of proinflammatory cytokines.

\section{Serum Immunoglobulins}

Finally, we quantified major antibody isotypes in mouse sera because previous studies suggested that spaceflight could affect
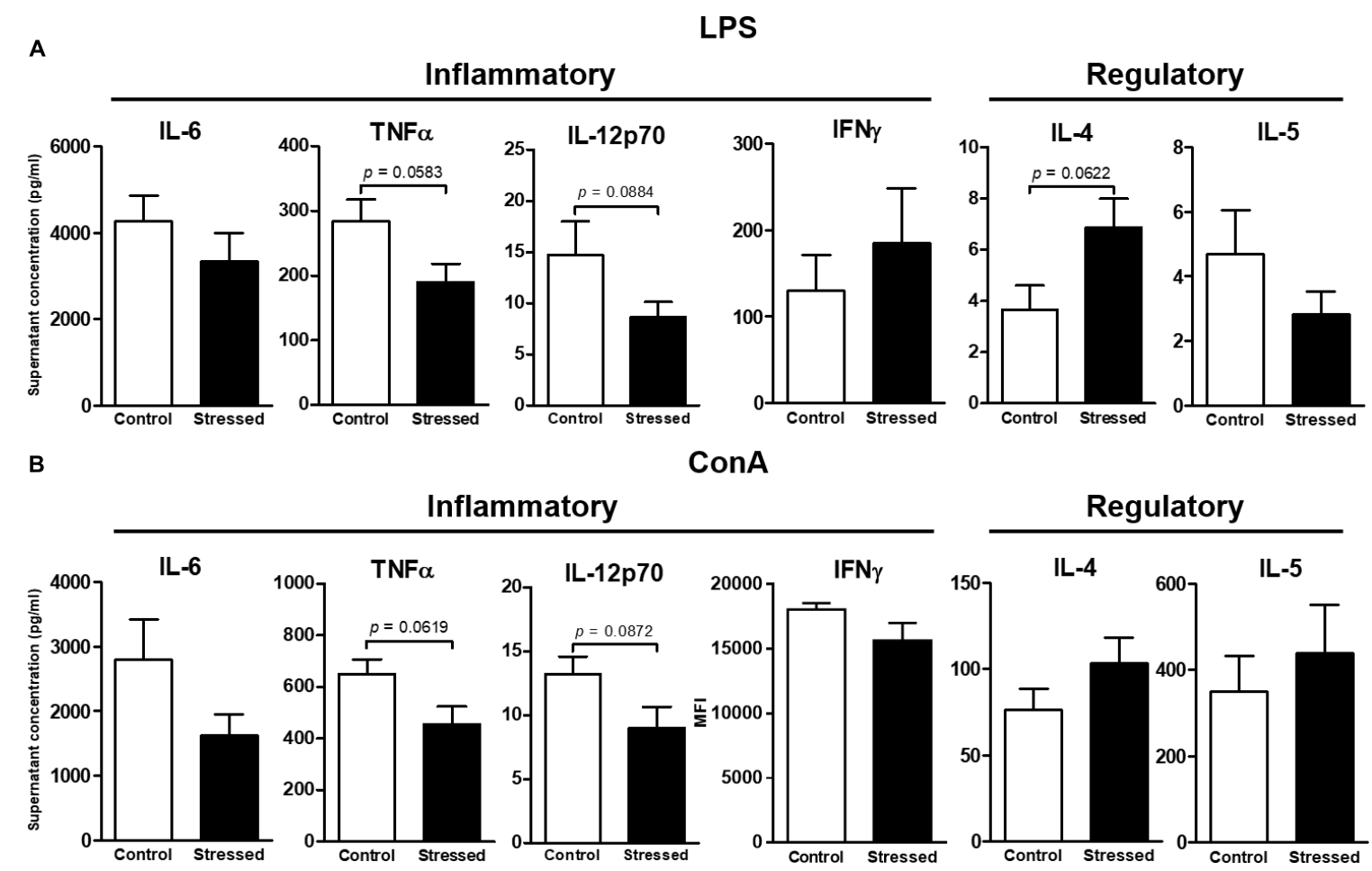

FIGURE 2 | Cytokines secreted by splenocytes of CUMS $(6 \leq n \leq 7)$ and control $(4 \leq n \leq 5)$ mice after 48 h of in vitro stimulation with LPS (A) or ConA (B). The concentrations of six Th1/Th2 cytokines in culture supernatants were determined using the ProcartaPlex ${ }^{\mathrm{TM}}$ kit and the Bio-Plex ${ }^{\circledR}$ instrument. Data are shown as means \pm SEM. In (B), MFI (mean fluorescence intensity) values are presented for IFN $\gamma$ because values were outside the standard curve established using the mixture of antigen standards provided by the manufacturer. Tendencies to significant differences were found using unpaired $t$-tests. Results representative of two CUMS exposures. 

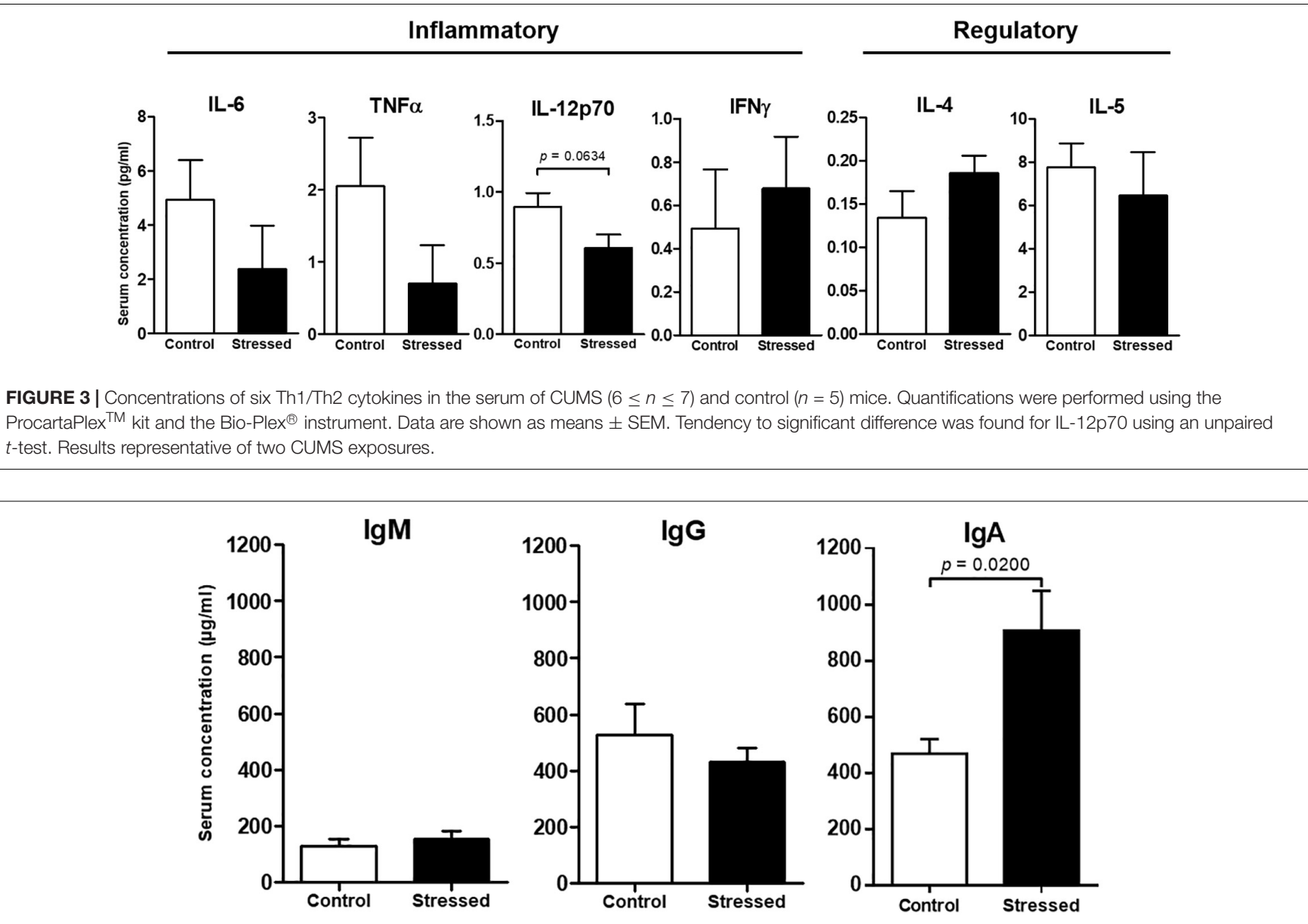

FIGURE 4 | Immunoglobulin concentrations in the sera of CUMS $(n=8)$ and control $(n=6)$ mice determined by ELISA. Histograms represent mean \pm SEM. Differences were found to be statistically significant using a Mann-Whitney test for IgA. No significant difference was found using an unpaired $t$-test for lgG and lgM. Results representative of two CUMS exposures.

their expression (Konstantinova et al., 1993; Boxio et al., 2005). Our analyses revealed that IgM and IgG concentrations were not significantly modified in the serum of CUMS mice (Figure 4). However, IgA concentration was significantly increased $(p=0.0200)$.

\section{DISCUSSION}

The aim of this study was to determine if a model involving the chronic exposure of mice to multiple unpredictable mild environmental and psychosocial stressors, CUMS, could replicate some immune changes reported during or after space missions. Such easy to implement model would be highly desirable given the limited access to undersea deployment, Antarctic winterover missions or Mars simulation experiments. Furthermore, using mice would overcome the limitations in the availability and the experimental protocols that can be carried out with human beings.

We first noted that after 3 weeks of CUMS exposure, a duration chosen to simulate a long flight at the human scale, mice did not present an activation of the hypothalamic-pituitaryadrenal (HPA) axis. Similarly, ISS crew generally adapt to the space environment (Crucian et al., 2016b). Usually, urine cortisol appears elevated early during flight, but returns to baseline following adaptation (Crucian et al., 2015).

A decrease of normalized splenic mass of 1.2 times was observed in CUMS mice. Similarly, previous studies have shown that spaceflight conditions reduce murine splenic mass by a 1.3 factor (Gridley et al., 2003; Baqai et al., 2009). However, CUMS did not modify splenic nucleated cells numbers and major lymphocyte sub-populations while changes in rat and mice splenic lymphocyte sub-populations were reported after spaceflight (Sonnenfeld et al., 1992; Pecaut et al., 2003; Baqai et al., 2009; Gridley et al., 2009). This difference is likely due to the fact that spaceflight induce a redistribution of body fluids (Vernikos, 1996) which is unlikely with CUMS. CUMS-induced lower splenic mass could result from a decrease in erythropoiesis because this physiological process was shown to be modulated by chronic psychosocial stress (Vignjevic et al., 2015). Interestingly, spaceflight conditions were also reported as having a negative impact on erythropoiesis (Davis et al., 1996). 
As indicated in the introduction of this paper, reduced $\mathrm{T}$ cell responses were reported after spaceflight. Less information is available about the effects on B cell responses but they are likely reduced too because less somatic hypermutations were noted in immunoglobulin heavy chains after inflight immunization (Bascove et al., 2011). It was also shown that B and $\mathrm{T}$ cell proliferative responses are reduced when mice were subjected to gravity changes (2G hypergravity or anti-orthostatic suspension) during 3 weeks (Guéguinou et al., 2012; Gaignier et al., 2014). In contrast, the responses of these lymphocytes were not modified after 3 weeks of exposure to socioenvironmental stressors (LPS and ConA are known to stimulate murine $\mathrm{B}$ and $\mathrm{T}$ cells, respectively). These data suggest that spaceflight-inducted lower lymphocyte responsiveness mainly result from gravity changes. This conclusion is in agreement with another study having shown that changes in gravity (hypergravity and microgravity) affect the expression of IgM heavy chain mRNAs, whereas other stressors encountered during a mission (radiation, confinement, disruption of the circadian rhythm, heat shock encountered during atmosphere re-entry onboard a Soyuz vehicle) did not (Huin-Schohn et al., 2013).

Serum cytokine levels were low in mice exposed to CUMS. This pattern is consistent with mice free of infection. A slight reduction of serum IL-12p70 concentration (1.5 times less) was noted in CUMS mice. This decrease of pro-inflammatory cytokine production appeared also after in vitro stimulation of splenocytes. Indeed, both IL-12p70 and TNF $\alpha$ levels tended to decline by an average 1.5 factor in culture medium after ConA and LPS stimulations. These statistical trends are perhaps due to the fact that after $48 \mathrm{~h}$ of stimulation we were not at the best moment to quantify cytokines. Furthermore, cytokine concentrations were shown to fluctuate during spaceflight (e.g., Crucian et al., 2015). Interestingly, it was recently shown that the levels of 10 out of 11 inflammatory or adaptive/regulatory cytokines remained low in the sera of astronauts during long-duration spaceflights (6 months) (Crucian et al., 2014). Nevertheless, when peripheral blood mononuclear cells of crewmembers involved in a long-duration mission in the ISS were stimulated with anti-CD3 and anti-CD28 to activate T cells or with PMA and ionomycin as a broader stimulus, these cytokines concentrations in culture supernatants were also decreased by an average 1.5 factor when comparing values obtained before launch with those determined on landing day (Crucian et al., 2015). Here, we did not observe a decline in adaptive/regulatory cytokine secretion. This difference could perhaps be because our mice experienced only a combination of various mild psychosocial and environmental stressors, while crewmembers additionally experienced microgravity. It may also be possible that mice adapt more rapidly or easily than human beings to stressful situations. Whatever the reasons are, these two independent studies are in agreement with results presented here.

Finally, we observed that the concentration of IgA was two times higher in the serum of CUMS mice. Such increase of IgA concentration was also noted in stressed people (Viena et al., 2012), in adult Pleurodeles walt after 6 months spent in the Mir space station (Boxio et al., 2005), mice exposed to hypergravity (Guéguinou et al., 2012) and people who faced 1 month of extreme Antarctic conditions (Mishra et al., 2012; Yadav et al., 2012). Together, these data suggest that IgA could be used as a stress biomarker.

\section{CONCLUSION}

This study shows that CUMS exposure increases serum IgA concentration, reduces spleen weight and tends to reduce the production of pro-inflammatory cytokines, as previously reported during or after space missions. However, this model does not reproduce spaceflight-induced modifications of splenic lymphocyte sub-populations and the lower responsiveness of lymphocytes. These data show that CUMS, which is an easy to implement model, could contribute to deepen our understanding of some spaceflight-induced immune alterations and could be useful to test countermeasures. In the future, it would be interesting to (i) perform a kinetic evaluation of immunological changes during CUMS exposure because physiological and immune changes may be dynamic and adaptation processes, despite resting periods included in the CUMS protocol, could be active during the experiment, (ii) examine the effects of CUMS exposure on specific lymphocyte subsets and (iii) submit latently infected mice to CUMS to see if this model could induce the reactivation of latent herpes viruses as frequently reported in astronauts.

\section{DATA ACCESSIBILITY}

Datasets generated for this study are included in the manuscript.

\section{AUTHOR CONTRIBUTIONS}

J-PF, CC-S, and LL conceived/designed the experiments. FG, CL-F, ES, JM, and J-LM performed the experiments. FG and CL-F analyzed the data. J-PF, FG, and CL-F wrote the manuscript in conjunction with other authors. All authors contributed to manuscript revision, read, and approved the submitted version.

\section{FUNDING}

This work was supported by the French Space Agency (DAR 4800000724, 4800000786, and 4800000841), the French Ministry of Higher Education and Research, the Université de Lorraine, the Région Lorraine, and the Institut National de la Santé et de la Recherche Médicale.

\section{ACKNOWLEDGMENTS}

We thank C. Ramacci for the technical help concerning cytokine quantification and T. Marday for helping with the CUMS procedure. 


\section{REFERENCES}

Baqai, F. P., Gridley, D. S., Slater, J. M., Luo-Owen, X., Stodieck, L. S., Ferguson, V. L., et al. (2009). Effects of spaceflight on innate immune function and antioxidant gene expression. J. Appl. Physiol. 106, 1935-1942. doi: 10.1152/ japplphysiol.91361.2008

Bascove, M., Guéguinou, N., Schaerlinger, B., Gauquelin-Koch, G., and Frippiat, J.-P. (2011). Decrease in antibody somatic hypermutation frequency under extreme, extended spaceflight conditions. FASEB J. 25, 2947-2955. doi: 10.1096/ fj.11- 185215

Bascove, M., Huin-Schohn, C., Guéguinou, N., Tschirhart, E., and Frippiat, J.-P. (2009). Spaceflight-associated changes in immunoglobulin VH gene expression in the amphibian Pleurodeles waltl. FASEB J. 23, 1607-1615. doi: 10.1096/fj.08121327

Boonyaratanakornkit, J. B., Cogoli, A., Li, C. F., Schopper, T., Pippia, P., Galleri, G., et al. (2005). Key gravity-sensitive signaling pathways drive T-cell activation. FASEB J. 19, 2020-2022. doi: 10.1096/fj.05-3778fje

Boxio, R., Dournon, C., and Frippiat, J.-P. (2005). Effets of a long-term spaceflight on immunoglobulin heavy chains of the urodele amphibian Pleurodeles waltl. J. Appl. Physiol. 98, 905-910. doi: 10.1152/japplphysiol.00957.2004

Chang, T. T., Walther, I., Li, C. F., Boonyaratanakornkit, J., Galleri, G., Meloni, M. A., et al. (2012). The Rel/NF-кB pathway and transcription of immediate early genes in T cell activation are inhibited by microgravity. J. Leukoc. Biol. 92, 1133-1145. doi: 10.1189/jlb.0312157

Choukèr, A. (2012). Stress Challenges and Immunity in Space - From Mechanisms to Monitoring and Preventive Strategies. Berlin: Springer-Verlag, doi: 10.1007/ 978-3-642-22272-6

Cogoli, A. (1993a). The effect of hypogravity and hypergravity on cells of the immune system. J. Leukoc. Biol. 54, 259-268.

Cogoli, A. (1993b). The effect of space flight on human cellular immunity. Environ. Med. 37, 107-116.

Cogoli, A., Tschopp, A., and Fuchsbislin, P. (1984). Cell sensitivity to gravity. Science 225, 228-230. doi: 10.1126/science.6729481

Cogoli-Greuter, M. (2004). Effect of gravity changes on the cytoskeleton in human lymphocytes Gravit. Space Biol. Bull. 17, 27-37.

Cohrs, R. J., Mehta, S. K., Schmid, D. S., Gilden, D. H., and Pierson, D. L. (2008). Asymptomatic reactivation and shed of infectious varicella zoster virus in astronauts. J. Med. Virol. 80, 1116-1122. doi: 10.1002/jmv.21173

Crucian, B., Babiak-Vazquez, A., Johnston, S., Pierson, D. L., Ott, C. M., and Sams, C. (2016a). Incidence of clinical symptoms during long-duration orbital spaceflight. Int. J. Gen. Med. 9, 383-391. doi: 10.2147/IJGM.S1 14188

Crucian, B., Johnston, S., Mehta, S., Stowe, R., Uchakin, P., Quiriarte, H., et al. (2016b). A case of persistent skin rash and rhinitis with immune system dysregulation onboard the International Space Station. J. Allergy Clin. Immunol. Pract. 4, 759-762. doi: 10.1016/j.jaip.2015.12.021

Crucian, B., Stowe, R., Quiriarte, H., Pierson, D., and Sams, C. (2011). Monocyte phenotype and cytokine production profiles are dysregulated by short-duration spaceflight. Aviat. Space Environ. Med. 82, 857-862. doi: 10.3357/ASEM.3047. 2011

Crucian, B., Stowe, R. P., Mehta, S., Quiriarte, H., Pierson, D., and Sams, C. (2015). Alterations in adaptive immunity persist during long-duration spaceflight. NPJ Microgravity 1:15013. doi: 10.1038/npjmgrav.2015.13

Crucian, B. E., Zwart, S. R., Mehta, S., Uchakin, P., Quiriarte, H. D., Pierson, D., et al. (2014). Plasma cytokine concentrations indicate that in vivo hormonal regulation of immunity is altered during long-duration spaceflight. J. Interferon Cytokine Res. 34, 778-786. doi: 10.1089/jir.2013.0129

Davis, T. A., Wiesmann, W., Kidwell, W., Cannon, T., Kerns, L., Serke, C., et al. (1996). Effect of spaceflight on human stem cell hematopoiesis: suppression of erythropoiesis and myelopoiesis. J. Leukoc. Biol. 60, 69-76. doi: 10.1002/jlb.60. 1.69

Frippiat, J.-P. (2013). Contribution of the urodele amphibian Pleurodeles waltl to the analysis of spaceflight-associated immune system deregulation. Mol. Immunol. 56, 434-441. doi: 10.1016/j.molimm.2013.06.011

Frippiat, J.-P., Crucian, B. E., de Quervain, D. J.-F., Grimm, D., Montano, N., Praun, S., et al. (2016). Towards Human Exploration of Space: The THESEUS review series on immunology research priorities. NPJ Microgravity 2:16040. doi: 10.1038/npjmgrav.2016.40
Gaignier, F., Schenten, V., De Carvalho Bittencourt, M., Gauquelin-Koch, G., Frippiat, J.-P., and Legrand-Frossi, C. (2014). Three weeks of murine hindlimb unloading induces shifts from $\mathrm{B}$ to $\mathrm{T}$ and from Th to Tc splenic lymphocytes in absence of stress and differentially reduces cell-specific mitogenic responses. PLoS One 9:e92664. doi: 10.1371/journal.pone.0092664

Ghislin, S., Ouzren-Zarhloul, N., Kaminski, S., and Frippiat, J.-P. (2015). Hypergravity exposure during gestation modifies the TCR $\beta$ repertoire of newborn mice. Sci. Rep. 5:9318. doi: 10.1038/srep09318

Globus, R. K., and Morey-Holton, E. (2016). Hindlimb unloading: rodent analog for microgravity. J. Appl. Physiol. 120, 1196-1206. doi: 10.1152/japplphysiol. 00997.2015

Gridley, D. S., Nelson, G. A., Peters, L. L., Kostenuik, P. J., Bateman, T. A., Morony, S., et al. (2003). Genetic models in applied physiology: selected contribution: effects of spaceflight on immunity in the C57BL/6 mouse. II. Activation, cytokines, erythrocytes, and platelets. J. Appl. Physiol. 94, 2095-2103. doi: 10.1152/japplphysiol.01053.2002

Gridley, D. S., Slater, J. M., Luo-Owen, X., Rizvi, A., Chapes, S. K., Stodieck, L. S., et al. (2009). Spaceflight effects on T lymphocyte distribution, function and gene expression. J. Appl. Physiol. 106, 194-202. doi: 10.1152/japplphysiol.91126. 2008

Guéguinou, N., Bojados, M., Jamon, M., Derradji, H., Baatout, S., Tschirhart, E., et al. (2012). Stress response and humoral immune system alterations related to chronic hypergravity in mice. Psychoneuroendocrinology 37, 137-147. doi: 10.1016/j.psyneuen.2011.05.015

Guéguinou, N., Huin-Schohn, C., Bascove, M., Bueb, J.-L., Tschirhart, E., LegrandFrossi, C., et al. (2009). Could spaceflight-associated immune system weakening preclude the expansion of human presence beyond Earth's orbit? J. Leukoc. Biol. 86, 1027-1038. doi: 10.1189/jlb.0309167

Hargens, A. R., and Vico, L. (2016). Long-duration bed rest as an analog to microgravity. J. Appl. Physiol. 120, 891-903. doi: 10.1152/japplphysiol.00935. 2015

Huin-Schohn, C., Guéguinou, N., Schenten, V., Bascove, M., Gauquelin-Koch, G., Baatout, S., et al. (2013). Gravity changes during animal development affect IgM heavy-chain transcription and probably lymphopoiesis. FASEB J. 27, 333-341. doi: 10.1096/fj.12-217547

Kaur, I., Simons, E. R., Castro, V. A., Ott, C. M., and Pierson, D. L. (2004). Changes in neutrophil functions in astronauts. Brain Behav. Immun. 18, 443-450. doi: 10.1016/j.bbi.2003.10.005

Kaur, I., Simons, E. R., Castro, V. A., Ott, C. M., and Pierson, D. L. (2005). Changes in monocyte functions of astronauts. Brain Behav. Immun. 19, 547-554. doi: 10.1016/j.bbi.2004.12.006

Kaur, I., Simons, E. R., Kapadia, A. S., Ott, C. M., and Pierson, D. L. (2008). Effect of spaceflight on ability of monocytes to respond to endotoxins of gramnegative bacteria. Clin. Vaccine Immunol. 15, 1523-1528. doi: 10.1128/CVI. 00065-08

Kimzey, S. L. (1977). "Hematology and immunology studies," in Biomedical Results from Skylab, eds R. S. Johnson and L. F. Dietlein (Washington, DC: NASA), 248-282.

Konstantinova, I. V., Rykova, M. P., Lesnyak, A. T., and Antropova, E. A. (1993). Immune changes during long-duration missions. J. Leukoc. Biol. 54, 189-201. doi: 10.1002/jlb.54.3.189

Lescale, C., Schenten, V., Djeghloul, D., Bennabi, M., Gaignier, F., Vandamme, F., et al. (2015). Hindlimb unloading, a model of spaceflight conditions, leads to decreased B lymphopoiesis similar to aging. FASEB J. 29, 455-463. doi: 10.1096/ fj. 14-259770

Martinez, E. M., Yoshida, M. C., Candelario, T. L., and Hughes-Fulford, M. (2015). Spaceflight and simulated microgravity cause a significant reduction of key gene expression in early T-cell activation. Am. J. Physiol. Regul. Integr. Comp. Physiol. 308, R480-R488. doi: 10.1152/ajpregu.00449.2014

Mehta, S. K., Stowe, R. P., Feiveson, A. H., Tyring, S. K., and Pierson, D. L. (2000). Reactivation and shedding of cytomegalovirus in astronauts during spaceflight. J. Infect. Dis. 182, 1761-1764. doi: 10.1086/317624

Meloni, M. A., Galleri, G., Camboni, M. G., Pippia, P., Cogoli, A., and CogoliGreuter, M. (2004). Modeled microgravity affects motility and cytoskeletal structures. J. Gravit. Physiol. 11, 197-198.

Meloni, M. A., Galleri, G., Pani, G., Saba, A., Pippia, P., and Cogoli-Greuter, M. (2011). Space flight affects motility and cytoskeletal structures in human monocyte cell line J-111. Cytoskeleton 68, 125-137. doi: 10.1002/cm.20499 
Meloni, M. A., Galleri, G., Pippia, P., and Cogoli-Greuter, M. (2006). Cytoskeleton changes and impaired motility of monocytes at modelled low gravity. Protoplasma 229, 243-249. doi: 10.1007/s00709-006-0210-2

Meshkov, D., and Rykova, M. (1995). The natural cytotoxicity in cosmonauts on board space stations. Acta Astronaut. 36, 719-726. doi: 10.1016/0094-5765(95) 00162-X

Mishra, K. P., Yadav, A. P., and Ganju, L. (2012). Antarctic harsh environment as natural stress model: impact on salivary immunoglobulins, transforming growth factor- $\beta$ and cortisol level. Indian J. Clin. Biochem. 27, 357-362. doi: 10.1007/s12291-012-0213-z

Pardon, M., Pérez-Diaz, F., Joubert, C., and Cohen-Salmon, C. (2000). Agedependent effects of a chronic ultramild stress procedure on open-field behaviour in B6D2F1 female mice. Physiol. Behav. 70, 7-13. doi: 10.1016/S00319384(00)00216-X

Pecaut, M. J., Nelson, G. A., Peters, L. L., Kostenuik, P. J., Bateman, T. A., Morony, S., et al. (2003). Genetic models in applied physiology: selected contribution: effects of spaceflight on immunity in the C57BL/6 mouse. I. Immune population distributions. J. Appl. Physiol. 94, 2085-2094. doi: 10.1152/ japplphysiol.01052.2002

Pierson, D. L., Stowe, R. P., Phillips, T. M., Lugg, D. J., and Mehta, S. K. (2005). Epstein-Barr virus shedding by astronauts during space flight. Brain Behav. Immun. 19, 235-242. doi: 10.1016/j.bbi.2004.08.001

Rykova, M. P., Antropova, E. N., Larina, I. M., and Morukov, B. V. (2008). Humoral and cellular immunity in cosmonauts after the ISS missions. Acta Astronaut. 63, 697-705. doi: 10.1016/j.actaastro.2008.03.016

Sciola, L., Cogoli-Greuter, M., Cogoli, A., Spano, A., and Pippia, P. (1999). Influence of microgravity on mitogen binding and cytoskeleton in Jurkat cells. Adv. Space Res. 24, 801-805. doi: 10.1016/S0273-1177(99)00078-2

Sonnenfeld, G., Mandel, A. D., Konstantinova, I. V., Berry, W. D., Taylor, G. R., Lesnyak, A. T., et al. (1992). Spaceflight alters immune cell function and distribution. J. Appl. Physiol. 73, 191S-195S. doi: 10.1152/jappl.1992.73.2.S191

Taylor, G. R., and Janney, R. P. (1992). In vivo testing confirms a blunting of the human cell-mediated immune mechanism during space-flight. J. Leukoc. Biol. 51, 129-132. doi: 10.1002/jlb.51.2.129

Thiel, C. S., Paulsen, K., Bradacs, G., Lust, K., Tauber, S., Dumrese, C., et al. (2012). Rapid alterations of cell cycle control proteins in human T lymphocytes in microgravity. Cell Commun. Signal. 10:1. doi: 10.1186/1478-811X-10-1
Vernikos, J. (1996). Human physiology in space. Bioessays 18, 1029-1037. doi: 10.1002/bies.950181215

Viena, T. D., Banks, J. B., Barbu, I. M., Schulman, A. H., and Tartar, J. L. (2012). Differential effects of mild chronic stress on cortisol and S-IgA responses to an acute stressor. Biol. Psychol. 91, 307-311. doi: 10.1016/j.biopsycho.2012. 08.003

Vignjevic, S., Budec, M., Markovic, D., Dikic, D., Mitrovic, O., Diklic, M., et al. (2015). Glucocorticoid receptor mediates the expansion of splenic late erythroid progenitors during chronic psychological stress. J. Physiol. Pharmacol. 66, 91-100. doi: 10.1111/jcmm.12167

Walther, I., Pippia, P., Meloni, M. A., Turrini, F., Mannu, F., and Cogoli, A. (1998). Simulated microgravity inhibits the genetic expression of interleukin-2 and its receptor in mitogen-activated T lymphocytes. FEBS Lett. 436, 115-118. doi: 10.1016/S0014-5793(98)01107-7

Woods, C. C., Banks, K. E., Gruener, R., and DeLuca, D. (2003). Loss of T cell precursors after spaceflight and exposure to vector-averaged gravity. FASEB J. 17, 1526-1528. doi: 10.1096/fj.02-0749fje

Woods, C. C., Banks, K. E., Lebsack, T. W., White, T. C., Anderson, G. A., Maccallum, T., et al. (2005). Use of a microgravity organ culture dish system to demonstrate the signal dampening effects of modeled microgravity during $\mathrm{T}$ cell development. Dev. Comp. Immunol. 29, 565-582. doi: 10.1016/j.dci.2004. 09.006

Yadav, A. P., Mishra, K. P., Ganju, L., and Singh, S. B. (2012). Wintering in Antarctica: impact on immune response of Indian expeditioners. Neuroimmunomodulation 19, 327-333. doi: 10.1159/000339512

Conflict of Interest Statement: The authors declare that the research was conducted in the absence of any commercial or financial relationships that could be construed as a potential conflict of interest.

Copyright (C) 2018 Gaignier, Legrand-Frossi, Stragier, Mathiot, Merlin, CohenSalmon, Lanfumey and Frippiat. This is an open-access article distributed under the terms of the Creative Commons Attribution License (CC BY). The use, distribution or reproduction in other forums is permitted, provided the original author(s) and the copyright owner are credited and that the original publication in this journal is cited, in accordance with accepted academic practice. No use, distribution or reproduction is permitted which does not comply with these terms. 